\title{
APPLICATION OF APRIORI ALGORITHM IN THE LAMINATION PROCESS IN YACHT PRODUCTION
}

\author{
Tacjana Niksa-Rynkiewicz \\ Michal Landowski \\ Paweł Szalewski \\ Gdańsk University of Technology, Poland
}

\begin{abstract}
The article specifies the dependence of defects occurring in the lamination process in the production of yachts. Despite great knowledge about their genesis, they cannot be completely eliminated. Authentic data obtained through cooperation with one of the Polish yacht shipyards during the years 2013-2017 were used for the analysis. To perform a simulation, the sample size was observed in 1450 samples, consisting of 6 models of yachts with closed and open deck. Finding the dependence of the occurrence of specific defects will allow for faster procedures and more effective quality control, which will contribute to lower costs. The use of new methods based on artificial intelligence related to Big Data allows for easier observation of dependencies in the complex structure of data from yacht production. The association rules were defined using the algorithm Apriori and define interdependent defects. A number of dependencies were found for the occurrence of production defects not obvious to technologists, but occurring with a high probability of coexistence. The presented research results may allow the planning process of production tasks to be improved.
\end{abstract}

Keywords: Apriori algorithm, quality control, laminate defects

\section{INTRODUCTION}

Today, fibrous polymer composites are used in all fields of technology, replacing traditional materials and giving new possibilities for design solutions, especially in relation to means of transport [1]. The most important group of these materials are layered composites - laminates. Polymer laminates are commonly used in the construction of small vessels such as yachts and pleasure boats, patrol boats for the police and army, fishing boats [40]. The length of these units is usually from a few to about 30 meters. Larger units are built for the needs of the navy and here their length is gradually increasing and the Swedish navy plays a leading role. The amagnetic corvettes built by it are even $90 \mathrm{~m}$ (and more) long [27]. However, this requires the use of modern materials and technologies. In addition to the reinforcement made of traditional glass fibers, carbon fibers with a high Young's modulus (stiffness) and high-strength aramid fibers are used $[11,39]$. Also, traditional polyester matrices in shipbuilding are replaced with vinyl ester or epoxy. Effective use of new materials in the construction of laminate elements requires the use of more advanced manufacturing techniques that guarantee better structural quality of the material associated with a smaller number of technological defects and the possibility of reducing the proportion of resin in the structure, which leads to an increase in strength, resistance to cracking and service life [12, 22, 29]

Currently, Poland is one of the European leaders in the market of producers of yachts and boats made of polymer laminates. However, most of our shipyards use the hand lay-up method of laminating process, some are working on implementing the infusion or Resin Transfer Moulding RTM method. However, this requires the employment of a professional workforce, which must be well paid, and this industry bases its profitability on the cheap labour that can be found in Poland, which ensures its competitiveness in relation to numerous manufacturers of this type of units in the West Europe. 
Attempts to introduce infusion technology are also associated with a certain risk of failure to obtain the appropriate quality of the material, when the process parameters (especially negative pressure and the density of the arrangement of vacuum tubes) are not properly selected by an inexperienced manufacturer [3, 45].

The number of defects arising during the lamination process is very large. It depends on many factors, such as the conditions in the production hall, the storage of materials, the method of reducing the laminate or even the level of personnel qualification. Vacuum methods allow to obtain a laminate with fewer technological defects, but sometimes they cause new defects not found in manual lamination - e.g. overdrying of the reinforcement $[22,43]$.

The lamination process in a shipyard should fulfil a number of requirements set out by the classification society Det Norske Veritas Germanischer Lloyd (DNV GL) Polish Register of Shipping (PRS). Good quality control is very important in the boat manufacturing process [31]. Therefore, tools supporting the assessment of defects play an important role. In the quality assessment process, most tests are visual tests, so it is important to clearly define what defects should be classified. Some particularly dangerous defects may be difficult to detect by visual testing, therefore other NDT methods are used $[5,16]$. For example, delamination can be detected by UT and RT. Due to expensive equipment and high qualifications of the person performing (interpreting) tests, they are usually not used in quality control in production in small shipyards. In such cases, old methods such as Tap Test work well $[5,34]$. The area of their occurrence is also important, which allows you to estimate the time needed to repair given defects or determine the lack of profitability of repair in the case of small boats. Therefore, quality control charts are kept in production facility.

Data from quality control cards may also allow finding defects in production processes if they are combined with delivery schedules, personnel work or the results of measurements of humidity and temperature conditions in the production facility.

The main concern of this article is issues related to the hand lay-up lamination process of yachts hulls. Podsiadlo and Tarelko in their works $[36,49]$ emphasized that the yacht production process can be separated into areas by the specifics of the activities: Planning, Project-Production-Delivery and Risk Reduction. The lamination process consists of a sequence of steps. There is a possibility of making mistakes at every stage of the lamination process - from storage and preparation of materials through the lamination process to the process of removing the cured hull from the mold. Some defects may arise due to the wrong process of designing a laminate structure, it is necessary to remember to adapt the design to the technological resources in the production company. There can be many reasons for these mistakes. The conducted research allowed to describe the relationships between the existing defects. They were written in the form of association rules. For this purpose, the A-priori algorithm was used. Observations made in one of the Polish small shipyards made it possible to pinpoint specific operations which contain lamination processes.

Computer aided mechanical and materials engineering has been facilitating the boat design process for many years.
It allows you to simulate many variants of shapes in order to obtain the best conditions for the flow of the yacht $[13,44]$, but also the selection of materials to obtain the optimal ratio of strength properties to weight and price $[18,46]$. The problems of determining the main factors needed for qualitative or quantitative analysis can be solved by means of classical statistical methods [32] as well as techniques based on the basic nearest neighbour algorithm [33] or fuzzy logic theory, by designing fuzzy systems [9].

For quality control and production management, the analysis of quality factors is very important. In the study [24], it was recognized that the Apriori algorithm and the analysis of association rules is one of the most frequently used techniques for quality analysis. The authors proposed the use of the Apriori algorithm with approximate sets to evaluate the mechanical properties of steel products. The analysis was carried out using data on the chemical composition and mechanical properties of the products. A similar approach brought many benefits described in the work [26].

\section{METHODS PRESENTED IN THE LITERATURE}

Depending on the model of yacht (its size) and the form in use, three main methods of lamination are used in the studied shipyard $[41,48]$ : Hand Lay-Up, Spray Lay-Up and Resin Transfer Moulding (RTM).

Currently, in the production of small boats, manual work with the use of simple tools - Hand Lay-Up, Spray Lay-Up. Vacuum methods such as RTM, Vacuum Bagging and Infusion are increasingly used in the production of advanced units and in larger shipyards $[10,30]$. Vacuum techniques allow for higher strength properties due to a higher volume fraction of reinforcement in the laminate [20]. Production with vacuum techniques requires higher qualifications of the personnel a big role in whether optimal properties will be obtained during the lamination process is played by the arrangement of the resin supply and outlet pipes (in-let and out-let), selection of the appropriate resin parameters (viscosity, gel time [35]. As a result, a large part of the industry still relies on manual techniques in the production process of small vessels [7]. Also, the staff is often unqualified, which reduces production costs, but does not allow the use of techniques that require compliance with the technological regime.

From a scientific point of view, it is interesting to develop new materials [21,22], newer methods [28] or modify older ones to improve the quality and strength of the laminates obtained $[14,19]$. This type of research is used by the industry in the production of more advanced units, e.g. racing boats [25]. Carbon or aramid fibers [42] and epoxy resins are often used there - these materials allow for higher strength parameters, but are much more expensive - hence the need to produce laminates with few defects and a large share of reinforcement $[15,17]$ Practices of this type make it possible to obtain boats of much lower weight - that is, increase in speed and range. Therefore, the boatbuilding industry is divided into two branches - low-cost production (oversized laminates with a lot of technological defects) and hi-tech production (advanced vacuum techniques to obtain thin laminates with 
few technological defects). Although science and industry are still moving forward $[8,47]$, there is a part of the industry that conservatively uses the simplest and cheapest production methods (hand lay-up and spray lay-up lamination).

Depending on the model of yacht (its size) and the form in use, three main methods of lamination are used in the studied shipyard: Hand Lay-Up, Spray Lay-Up and Resin Transfer Moulding (RTM).

From the methods that can be implemented for research, the method that is the best from the point of view of our research was selected due to:

- it must allow the observation of the largest number of defects - the observations from hand lay-up were used for the study, due to the possibility of a large number of defects (large number of defects) during the technological process compared to other more advanced methods (RTM).

- it must make it possible to observe the relationship between defects with the cheapest possible technology

- the method should be widely used in small shipyards.

The results of the quality inspection of yachts manufactured by hand laminating were selected for the research.

\section{NOVELTY ELEMENTS}

So far, no cross-relationships of material defects formation during the use of the manual laminating method have been described in the literature. Observation of these dependencies makes it possible to eliminate them, and thus the working time can be reduced. The method makes it easier to locate the most sensitive stages of production. Thanks to the prior identification of coexisting defects that disqualify the product for further processing, it will be possible to develop a "quick elimination path" in quality control. The research carried out on the lamination method causing the highest number of defects will allow to check the possibility of using quality control support in the production of laminates also with other more advanced production methods. At the same time, these are preliminary studies to introduce a time-cost analysis of the profitability of repairs and to create tools to reduce inspection time while maintaining a similar level of quality control.

\section{DESCRIPTION OF THE PROBLEM}

The yacht production process, regardless of the method of their production, is associated with the occurrence of defects in the laminate. Defects should be eliminated at individual stages of production through appropriate process control or by repairing the finished product. But even the best-controlled process cannot protect itself from defects.

Defects should be detected by means of quality control and the possibility of repairing them should be assessed (due to the economy and repair techniques) or the hull scrapped when the time and cost of repairing the defects exceed the assumed acceptable level.

\section{MONITORING OF THE LAMINATION PROCESS}

The manufacturing process strongly depends on the environmental conditions of the production. In the analysed production process, humidity and temperature are continuously monitored with the use of thermos-hygrometers both in the production hall and in the material warehouse. Factory premises are well ventilated in accordance with the recommendations of protecting workers' health. The rooms are heated by a boiler room with individual temperature control. The temperature of the storage and processing environment was selected on the basis of the technological cards of the components.

\section{POSSIBLE DEFECTS IN THE LAMINATION PROCESS}

The lamination process is burdened with the risk of occurrence of many defects that may affect the quality of the end product. A properly executed monitoring process described in the chapter "Lamination Process Monitoring" allows the number of mistakes to be reduced. The elements of the yacht hull are assessed during quality control. The list of observed defects during this stage is presented in Table 1.

\begin{tabular}{|c|c|c|}
\hline $\begin{array}{l}\text { Defect } \\
\text { symbol }\end{array}$ & $\begin{array}{l}\text { Short name } \\
\text { of defect }\end{array}$ & Name / description of defect \\
\hline A & Air Bubles & $\begin{array}{l}\text { Air bubbles of up to } 15 \mathrm{~cm} \text { long or area } \\
\text { similar to } \mathrm{A} 5^{\star}\end{array}$ \\
\hline B & $\begin{array}{l}\text { Burnt } \\
\text { surfaces }\end{array}$ & Burnt surfaces (area similar to $\mathrm{A} 4^{\star}$ ) \\
\hline $\mathrm{C}$ & $\begin{array}{l}\text { Surpluses to } \\
\text { grind }\end{array}$ & $\begin{array}{l}\text { Surpluses or loss of material - repair by } \\
\text { grinding }\end{array}$ \\
\hline $\mathrm{D}$ & Wrinkling & Wrinkling or "alligatoring" \\
\hline $\mathrm{E}$ & Scratches & $\begin{array}{l}\text { Small scratches (area similar to } \mathrm{A} 4^{*} \text { ) and } \\
\text { scratches to be repaired }\end{array}$ \\
\hline $\mathrm{F}$ & Cracks & $\begin{array}{c}\text { Cracks (up to } 25 \mathrm{~cm} \text { long or area similar } \\
\text { to } \mathrm{A} 4^{*} \text { ) }\end{array}$ \\
\hline G & Inprint & Fibre Pattern (inprint) \\
\hline $\mathrm{H}$ & Deformation & Deformation \\
\hline I & $\begin{array}{l}\text { Demould } \\
\text { defects }\end{array}$ & $\begin{array}{l}\text { Demould defects (up to } 25 \mathrm{~cm} \text { long or area } \\
\text { similar to } \mathrm{A}^{*} \text { ) }\end{array}$ \\
\hline $\mathrm{J}$ & Delaminations & $\begin{array}{l}\text { Delaminations and other construction } \\
\text { laminate defects }\end{array}$ \\
\hline K & Porosity & Porosity \\
\hline $\mathrm{L}$ & Dimplings & Accelerator spots / Dimplings \\
\hline M & $\begin{array}{l}\text { Dry } \\
\text { reinforcement }\end{array}$ & Dry glass reinforcements \\
\hline $\mathrm{N}$ & Spots & Spots \\
\hline $\mathrm{O}$ & $\begin{array}{l}\text { Anti-sliding } \\
\text { defects }\end{array}$ & defects of Anti-sliding surface $(3 \mathrm{~cm} 2)$ \\
\hline $\mathrm{P}$ & Matte finish & Matte finish \\
\hline Q & Other defects & Other defects \\
\hline
\end{tabular}


The defects of the structural laminate and delamination (J), areas of dry reinforcement (M) and large air bubbles (A) are the most serious defects occurring in the lamination process - their presence significantly reduces the strength of the structure. The remaining technological defects assessed during the quality control are cosmetic defects that reduce the value of the final product or contribute indirectly to the reduction of the service life of laminates [38].

Dry reinforcement $(\mathrm{M})$ is caused by the resin's gelling time being too short, which may be caused by failure to meet temperature and humidity conditions or incorrect proportions of resin and hardener. It also happens that dry reinforcement $(\mathrm{M})$ occurs by underestimating the amount of resin needed to laminate the laminate layer. Damage to the anti-skid surface $(\mathrm{O})$ on the deck can be caused by improper preparation of the mold (I), inaccurate application of the separating layer or not preparing it (polishing and dust removal). This defect $(\mathrm{O})$ can also be due to the use of an inappropriate lamination technology or laminate demoulding process. Repairing such damage $(\mathrm{O})$ often involves removing a significant area and replacing it with a new anti-skid element. Scratches on the hull (E) usually occur during rough handling of the final product, but they can also appear at the beginning of the process by improper grinding and polishing of the mold, not cleaning the mold surface before applying the first layer of gelcoat.

The smoothness and general condition of the yacht's outer surface largely depends on the quality of the mold preparation, because any imperfections in the preparation will be transferred into the form of defects (e.g. scratches (E), matt surface $(\mathrm{P})$, stains $(\mathrm{N})$ and porosity $(\mathrm{K})$ ) on the surface of the gelcoat. In some cases, poor preparation of the mold failure to cover the mold with molding gelcoat causes the reinforcement texture to reflect on the gelcoat surface $(G)$. This is an defect that needs to be caught at an early stage of production so that subsequent boats produced in this form do not have to be repaired. The so-called INPRINT (G), i.e. the mapping of the reinforcement texture on the surface of the gelcoat, occurs when the gelcoat layer is too thin [37].

Repairing this type of damage $(\mathrm{G})$ involves grinding a part of the material (gelcoat and part of construction laminate) and applying a layer of gelcoat from the outside, and then grinding and polishing to obtain a smooth surface. Elimination of this type of defects is possible already at the laminate design stage by using the so-called SkinCoat layers consisting of a resin layer with a thin mat laid on a gelcoat before applying the structural laminate [10]. Air bubbles (A) may be caused by irregular application of the resin, lack of the resin degassing process (partially, when the resin is mechanically mixed with the hardener, we introduce air bubbles into it), incorrect temperature (outside the range required by the technological card) in the working room. Such defects may occur in both the gelcoat and the structural laminate. A small amount of small air bubbles in the structural laminate is natural and does not significantly reduce the strength properties of the laminate, but large bubbles act as dry reinforcement and weaken the strength of the element [4]. Air bubbles (A) in the gelcoat layer can cause faster degradation of the protective layer, which is the gelcoat, and allow water to penetrate the structural laminate [23].

Wrinkling, also known as "alligatoring" (D), is a defect of a gelcoat caused by too quick deformation of the laminate, too thin a layer or insufficient cure of the gelcoat. The gelcoat layer plays an aesthetic role, but you should not forget about its protective effect. Structural laminate is much less resistant to water, therefore appropriate protective layers (gelcoat or complex systems consisting of gelcoat, skincoat and barriercoat) must be applied on its surface [23].

When performing repairs using complex protection systems, we are not able to recreate the correct layout and thickness of these layers. Therefore, when using advanced materials, a high technological regime should be maintained in order to avoid defects. Most gelcoats are prepared by the manufacturer in the appropriate colour, but the pigment contained in them may be subject to slow sedimentation or agglomeration. Poor mixing of the gel coat prior to application may result in stains $(\mathrm{N})$ and colour irregularities. If pigments or dyes are used to change the colour of the gelcoat, failure to care for the proportions and thorough mixing may also cause stains and colour irregularities (N). Such defects can also be caused by the action of UV rays on the uncured product [6].

A matt finish $(\mathrm{P})$ or rough surface can be the result of poor hardening, often caused by poor mixing of the resin with the hardener. It may also be the result of poor laminate deformation due to mistakes made during the application and preparation of the release layer. There are also defects resulting from the degradation of materials during storage - incorrect temperature and humidity conditions, contamination with grinding products, dust, expiry date (for resins).

Some of the defects result from incorrect proportions of resin and hardener, others from too thick or too thin gel coat. The influence of the ambient temperature is also significant. From this information it can be concluded that some of the material defects depend on common factors. Such conclusions contributed to the issue of creating association rules for defects occurring in the lamination process.

\section{PROBLEM FORMULATION}

The current research work and the results presented in the literature concern the influence of production methods on the mechanical properties or service life of laminates. Science focuses on the development of new materials and manufacturing techniques, and not on the analysis of the causes of defects in old but still widely used methods. This work is aimed at combining modern data processing techniques with the analysis of technological defects in the basic manufacturing technique.

It is easy to indicate works which describe the causes of defects even in guides and manufacturers' manuals [50, 51], but there are no works on dependencies and rules between coexisting defects.

The goal of this research is to determine association rules to improve the monitoring stage. A system of knowledge that considers issues concerning dependencies of the defects 
occurring can allow prediction of the possible consequences of the occurrence of similar defects, allowing repair processes and additional costs to be minimized.

\section{APRIORI ALGORITHM AND FORMULATION OF ASSOCIATION RULES}

The algorithms Apriori and Apriori TID for discovering strong binary association rules were described in 1994 [2]. Let $\boldsymbol{L}=\left\{l_{1}, l_{2}, \ldots, l_{m}\right\}$ describe the set of elements. A transaction of elements or transaction is any nonempty subset $\boldsymbol{T}$ of $\boldsymbol{L}$, $T \subseteq L i T \neq \varnothing$.

$T$ supports an element $x \in L$ if $x$ is $T, x \in T$. $T$ supports set $\boldsymbol{X} \subseteq \boldsymbol{L}$ if $\boldsymbol{T}$ supports every element in $\boldsymbol{X}, \boldsymbol{X} \subseteq \boldsymbol{T}$. The size of transaction $T$, size $(T)$, is the number of elements in $T$. The set of input data $D$ is called the set of $T, D=\left(T_{1}, T_{2}, \ldots, T_{n}\right)$ where $T_{i} \subseteq L, i=1,2, \ldots, n$.

The binary association rule is the relation $X \rightarrow Y$, where $\boldsymbol{X} \subset \boldsymbol{L}, \boldsymbol{Y} \subset \boldsymbol{L} i \boldsymbol{X} \cap \boldsymbol{Y} \neq \varnothing . \boldsymbol{X}$ is called the antecedent of the rule, and $Y$ is the consequent of the rule. The binary association rule $\boldsymbol{X} \rightarrow \boldsymbol{Y}$ has $\operatorname{supp}(\boldsymbol{X} \rightarrow \boldsymbol{Y})$ in the data set $\boldsymbol{D}, 0 \leq \operatorname{supp} \leq 1$.

$$
\operatorname{supp}(\boldsymbol{X} \rightarrow \boldsymbol{Y})=\frac{\mid\left\{\boldsymbol{T}_{i} \in \boldsymbol{D} \mid \boldsymbol{T}_{i} \text { wspiera } \boldsymbol{X} \cup \boldsymbol{Y}\right\} \mid}{|\boldsymbol{D}|},
$$

confidence $\operatorname{conf}(\boldsymbol{X} \rightarrow \boldsymbol{Y})$ in the database $\boldsymbol{D}, 0 \leq \operatorname{conf} \leq 1$ :

$$
\operatorname{conf}(\boldsymbol{X} \rightarrow \boldsymbol{Y})=\frac{\mid\left\{\boldsymbol{T}_{i} \in \boldsymbol{D} \mid \boldsymbol{T}_{i} \text { wspiera } \boldsymbol{X} \cup \boldsymbol{Y}\right\} \mid}{\mid\left\{\boldsymbol{T}_{j} \in \boldsymbol{D} \mid \boldsymbol{T}_{j} \text { wspiera } \boldsymbol{X}\right\} \mid},
$$

and $\operatorname{lift}(\boldsymbol{X} \rightarrow \boldsymbol{Y})$ in the database $\mathbf{D}$

$$
\operatorname{lift}(\boldsymbol{X} \rightarrow \boldsymbol{Y})=\frac{\operatorname{conf}(\boldsymbol{X} \rightarrow \boldsymbol{Y})}{\operatorname{supp}(\boldsymbol{Y})} .
$$

Support is a value measure of the association rule, because it defines the number of transactions in set $\mathbf{D}$ which confirm said rule.

Apriori pseudocode

INPUT: Database

OUT: Large item set

$/ / \boldsymbol{L}=\left\{l_{1}, l_{2}, \ldots, l_{m}\right\}$

$L_{1}=\{$ large one-item sets $\}$

for $\left(\mathrm{k}=2 ; L_{\mathrm{k}-1} \neq \varnothing ; \mathrm{k}++\right)$

//New candidates

$C_{\mathrm{k}}=$ apriori_gen $\left(L_{\mathrm{k}-1}\right)$;

for all transactions $t \in \mathbf{D}$

//Candidates in $\mathrm{t}$

$C_{\mathrm{t}}=\operatorname{subset}\left(C_{\mathrm{k}}, \mathrm{t}\right)$;

for all candidates $\mathrm{c} \in C_{\mathrm{t}}$ )

c.count ++

end

$F_{\mathrm{k}}=\left\{\mathrm{c} \in C_{\mathrm{k}} \mid \mathrm{c} \cdot\right.$ count $>=$ minsup $\}$;

end

end

Answer $=U_{k} L_{k}$

\section{SIMULATIONS}

The lamination process was observed in 2013-2017. The data used in the research were collected during observation of the production of a 6 yachts models with the following parameters: length 6-9 $\mathrm{m}$. and width $2.5-3 \mathrm{~m}$,

\begin{tabular}{|c|c|c|c|c|c|c|}
\hline No. & Name & $\begin{array}{c}\text { Length } \\
{[\mathrm{m}]}\end{array}$ & $\begin{array}{c}\text { Width } \\
\text { [m] }\end{array}$ & $\underset{[\mathrm{m}]}{\operatorname{Immersion}}$ & $\begin{array}{c}\text { Total } \\
\text { mass } \\
{[\mathrm{kg}]}\end{array}$ & $\begin{array}{c}\text { Set sample } \\
\text { size } \\
{[\mathrm{u}]}\end{array}$ \\
\hline 1 & CC6LA & 6.4 & 2.48 & 0.43 & 1036 & 542 \\
\hline 2 & CW6L & 6.59 & 2.48 & 0.66 & 1050 & 365 \\
\hline 3 & CW8K & \multirow{2}{*}{8.42} & \multirow{2}{*}{2.98} & \multirow{2}{*}{0.75} & \multirow{2}{*}{2540} & 99 \\
\hline 4 & CW8P & & & & & 102 \\
\hline 5 & MF8K & \multirow{2}{*}{8.90} & \multirow{2}{*}{2.99} & \multirow{2}{*}{0.63} & \multirow{2}{*}{3060} & 168 \\
\hline 6 & MF8P & & & & & \\
\hline
\end{tabular}
immersion $0.4-0.75 \mathrm{~m}$ and total mass $1000-3000 \mathrm{~kg}$ (Tab. 2).

Tab. 2. Information about model observed in 2013-2017

Each unit produced is controlled. The number of faults and mistakes is described quantitatively on a special card. An example of a quality control card is shown in Fig. 1.

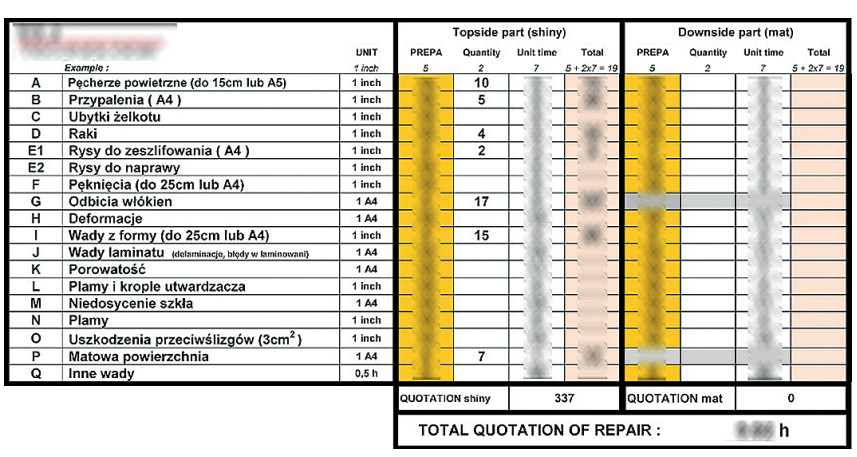

Fig. 1. Example of a quality control card

Based on the information thus compiled, a set was created $T_{i}$. It contains a list of all mistakes that were made in the production of each yacht. An example data set (TID), $T_{i}$ for $i=1 . . n$, is presented in Table 3 .

Tab. 3. Set of sample transactions $\boldsymbol{T}_{i}, n=5$

\begin{tabular}{|c|c|}
\hline Transaction ID & Item Defects \\
\hline$T_{1}$ & $\{\mathrm{~A}, \mathrm{~B}, \mathrm{C}, \mathrm{D}, \mathrm{F}, \mathrm{H}, \mathrm{I}, \mathrm{O}, \mathrm{P}\}$ \\
\hline$T_{2}$ & $\{\mathrm{~A}, \mathrm{C}, \mathrm{F}, \mathrm{H}, \mathrm{I}, \mathrm{O}, \mathrm{P}\}$ \\
\hline$T_{3}$ & $\{\mathrm{~A}, \mathrm{~B}, \mathrm{C}, \mathrm{G}, \mathrm{I}, \mathrm{J}, \mathrm{O}, \mathrm{P}\}$ \\
\hline$T_{4}$ & $\{\mathrm{~A}, \mathrm{~B}, \mathrm{~F}, \mathrm{H}, \mathrm{I}, \mathrm{K}, \mathrm{O}, \mathrm{P}\}$ \\
\hline$T_{5}$ & $\{\mathrm{~A}, \mathrm{~B}, \mathrm{C}, \mathrm{D}, \mathrm{E}, \mathrm{H}, \mathrm{I}, \mathrm{J}, \mathrm{O}, \mathrm{P}\}$ \\
\hline
\end{tabular}

First, the elements of the $k$-set, for $k=1$, were determined. An example of samples occurring in this form is described in Tables 3 and 4. Information about the occurrence of the specified defect during the production of the $i$-th yacht $\left(T_{i}\right)$. The number of all transactions is $n=542$. Binary representation was used in the Apriori algorithm as shown in the pseudocode. 
Tab. 4. An example binary table $\boldsymbol{T}_{i}, n=5$

\begin{tabular}{|c|c|c|c|c|c|}
\hline Defect symbol & $T_{1}$ & $T_{2}$ & $T_{3}$ & $T_{4}$ & $T_{5}$ \\
\hline A & 1 & 1 & 1 & 1 & 1 \\
\hline B & 1 & 0 & 1 & 1 & 1 \\
\hline C & 1 & 1 & 1 & 0 & 1 \\
\hline D & 1 & 0 & 0 & 0 & 1 \\
\hline E & 0 & 0 & 0 & 0 & 1 \\
\hline F & 1 & 1 & 0 & 1 & 0 \\
\hline G & 0 & 0 & 1 & 0 & 0 \\
\hline H & 1 & 1 & 0 & 1 & 1 \\
\hline I & 1 & 1 & 1 & 1 & 1 \\
\hline J & 0 & 0 & 1 & 0 & 1 \\
\hline K & 0 & 0 & 0 & 1 & 0 \\
\hline L & 0 & 0 & 0 & 0 & 0 \\
\hline M & 0 & 0 & 0 & 0 & 0 \\
\hline N & 0 & 0 & 0 & 0 & 0 \\
\hline O & 1 & 1 & 1 & 1 & 1 \\
\hline P & 0 & 0 & 0 & 0 & 0 \\
\hline & 1 & 1 & 0 & 1 & 1 \\
\hline & 0 & 0 & 0 & 1 & 1 \\
\hline
\end{tabular}

Following the algorithm described in Chapter 3, the full set of samples for all yachts was analysed. The procedure is presented in detail only for the (CC6LA) case (Tab. 5), where $n=542$.

Tab. 5. Set of values for all defects and $\left(C_{1}\right), \operatorname{conf}\left(C_{1}\right)$, and item set $C_{1}, F_{1}$

\begin{tabular}{|c|c|c|c|}
\hline Defect symbol & $\operatorname{count}\left(C_{1}\right)$ & $\operatorname{conf}\left(C_{1}\right)(\%)$ & $F_{1}$ \\
\hline $\mathrm{A}$ & 542 & 100 & Yes \\
\hline B & 505 & 93.2 & Yes \\
\hline $\mathrm{C}$ & 366 & 67.5 & No \\
\hline $\mathrm{D}$ & 192 & 35.4 & No \\
\hline E & 180 & 33.2 & No \\
\hline $\mathrm{F}$ & 207 & 38.2 & No \\
\hline G & 426 & 78.6 & No \\
\hline $\mathrm{H}$ & 103 & 19 & No \\
\hline I & 534 & 98.5 & Yes \\
\hline $\mathrm{J}$ & 7 & 1.3 & No \\
\hline $\mathrm{K}$ & 65 & 12 & No \\
\hline $\mathrm{L}$ & 58 & 10.7 & No \\
\hline M & 9 & 1.7 & No \\
\hline $\mathrm{N}$ & 6 & 1.1 & No \\
\hline $\mathrm{O}$ & 343 & 63.3 & No \\
\hline $\mathrm{P}$ & 526 & 97 & Yes \\
\hline Q & 3 & 0.6 & No \\
\hline
\end{tabular}

The best results for the Apriori algorithm were acquired for values of $\sup =0.9$ and $\operatorname{conf}=0.8$. Using the full data set $n=542$. For the purpose of building the frequent sets, $k=2$ elements of were used. Information on the elements is listed in Tables 5 and 6.

The most common defects are: A, B, I and P, less frequent defects: G, C. Other defects do not occur more often than $40 \%$ of the yachts produced. A and B are rather independent of each other. The defect I is generated by causes other than the $\mathrm{A}$ and $\mathrm{B}$ defects, while the $\mathrm{P}$ defect may depend on the $B$ and / or I defects. The next step is to determine frequent 2-element sets (Table 6).

Tab. 6. Set of values for all defects, count $\left(C_{2}\right)$, conf $\left(C_{2}\right)$, and item set $C_{2}, F_{2}$

\begin{tabular}{|c|c|c|c|}
\hline$X$ & count $\left(C_{2}\right)$ & $\operatorname{conf}(X)$ & $X_{2}$ \\
\hline$\{\mathrm{A}, \mathrm{B}\}$ & 505 & 93.2 & Yes \\
\hline$\{\mathrm{A}, \mathrm{G}\}$ & 426 & 78.6 & No \\
\hline$\{\mathrm{A}, \mathrm{I}\}$ & 534 & 98.5 & Yes \\
\hline$\{\mathrm{A}, \mathrm{P}\}$ & 526 & 97 & Yes \\
\hline$\{\mathrm{B}, \mathrm{G}\}$ & 402 & 74.2 & No \\
\hline$\{\mathrm{B}, \mathrm{I}\}$ & 502 & 92.6 & Yes \\
\hline$\{\mathrm{B}, \mathrm{P}\}$ & 495 & 91.3 & No \\
\hline$\{\mathrm{G}, \mathrm{I}\}$ & 423 & 78.3 & No \\
\hline$\{\mathrm{G}, \mathrm{P}\}$ & 419 & 77.3 & No \\
\hline$\{\mathrm{I}, \mathrm{P}\}$ & 521 & 96.1 & Yes \\
\hline
\end{tabular}

To create three-element frequent sets $k=3$, the sets $\{A, B\}$, $\{A, I\},\{B, I\},\{I, P\}$ were selected (Table 7).

Tab. 7. Set of values for all defects, count $\left(C_{3}\right)$, conf $\left(C_{3}\right)$, and item set $C_{3}, F_{3}$

\begin{tabular}{|c|c|c|}
\hline$X$ & $\operatorname{conf}(X)$ & $F_{3}$ \\
\hline$\{\mathrm{A}, \mathrm{B}, \mathrm{I}\}$ & 502 & Yes \\
\hline$\{\mathrm{A}, \mathrm{B}, \mathrm{P}\}$ & 495 & No \\
\hline$\{\mathrm{A}, \mathrm{I}, \mathrm{P}\}$ & 521 & Yes \\
\hline
\end{tabular}

In the process of building association rules, only $\{\mathrm{A}, \mathrm{B}, \mathrm{I}\}$ and $\{\mathrm{A}, \mathrm{I}, \mathrm{P}\}$ were taken into account. The algorithm allowed 32 association rules to be defined (Fig. 7).

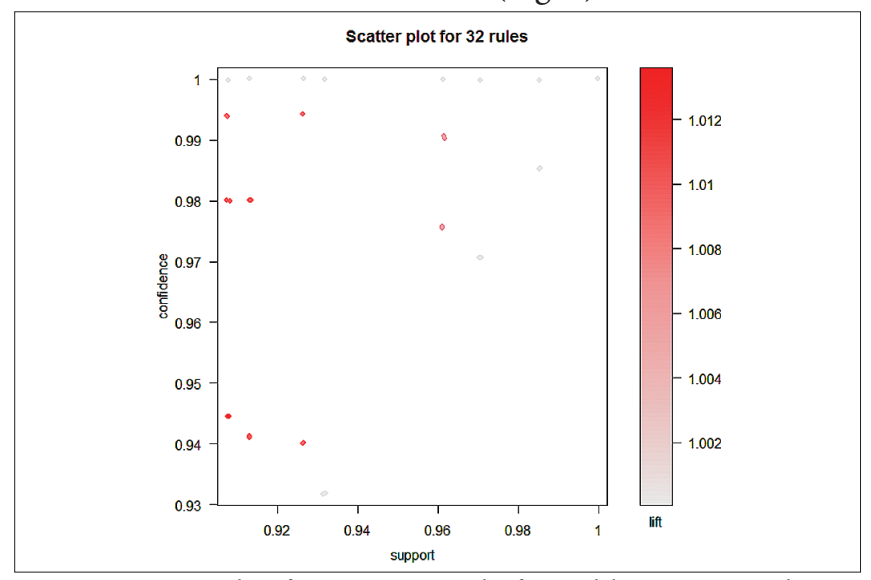

Fig. 7. Scatter plot of 32 association rules for model J1CC6LA; results for Apriori algorithm were acquired for values of $\operatorname{supp}=0.9$ and conf $=0.8$ 
The value lift $=1$ indicates defects occurring independently of each other. A value of lift $>1$ indicates a positive correlation while lift $<1$ indicates a negative correlation. After analysing the results obtained, the most important rules were selected (Fig. 8).

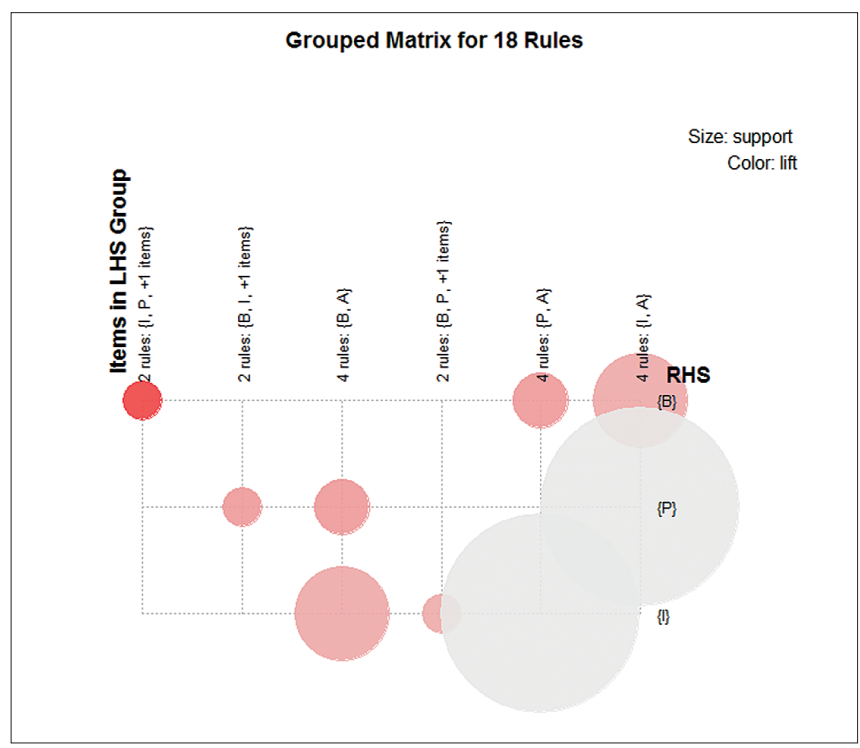

Fig. 8. Grouped matrix for 18 rules, where lift $>1$ (Model: J1CC6LA, $\operatorname{supp}=0.9, \operatorname{conf}=0.8$ )

After elimination of unnecessary rules, 18 rules were left in the set. The lift value indicates high associations between $\{\mathrm{P}\}$, $\{B\}$, and $\{I\}$, respectively, and "matte finish", "burnt surfaces" (A4), and "moulds defects".

The lamination process of other yacht models, namely: CC6LA, CW6L, CW8K, CW8P, MF8K and MF8P, was analysed analogically. Correlations between defects that are rare in the laminating process are particularly interesting. Therefore, the value of the parameter was taken from the range $<0.1$ to $0.9>$ (Tables $8-13$ ).

Tab. 8. Set of information about association rules with values: $\operatorname{supp}(X \rightarrow Y) \geq 0.9$; conf $(X \rightarrow Y) \geq 0.9$; lift $(X \rightarrow Y)>1$; model: J2(C6LA)

\begin{tabular}{|c|c|c|c|}
\hline$X \rightarrow Y$ & $\operatorname{supp}\left(^{*}\right)$ & $\operatorname{conf}\left(^{*}\right)$ & lift $\left(^{*}\right)$ \\
\hline$\{\mathrm{P}\} \Rightarrow\{\mathrm{B}\}$ & 0.9132841 & 0.9801980 & 1.010014 \\
\hline$\{\mathrm{B}\} \Rightarrow\{\mathrm{P}\}$ & 0.9132841 & 0.9410646 & 1.010014 \\
\hline$\{\mathrm{I}, \mathrm{P}\} \Rightarrow\{\mathrm{B}\}$ & 0.9077491 & 0.9443378 & 1.013527 \\
\hline$\{\mathrm{B}, \mathrm{I}\} \Rightarrow\{\mathrm{P}\}$ & 0.9077491 & 0.9800797 & 1.009892 \\
\hline$\{\mathrm{B}\} \Rightarrow\{\mathrm{I}\}$ & 0.9261993 & 0.9940594 & 1.008952 \\
\hline$\{\mathrm{I}\} \Rightarrow\{\mathrm{B}\}$ & 0.9261993 & 0.9400749 & 1.008952 \\
\hline$\{\mathrm{B}, \mathrm{P}\} \Rightarrow\{\mathrm{I}\}$ & 0.9077491 & 0.9939394 & 1.008830 \\
\hline$\{\mathrm{P}\} \Rightarrow\{\mathrm{I}\}$ & 0.9612546 & 0.9904943 & 1.005333 \\
\hline$\{\mathrm{I}\} \quad>\{\mathrm{P}\}$ & 0.9612546 & 0.9756554 & 1.005333 \\
\hline
\end{tabular}

Tab. 9. Set of information about association rules with values: $\operatorname{supp}(X \rightarrow Y) \geq 0.8$; $\operatorname{conf}(X \rightarrow Y) \geq 0.9$; lift $(X \rightarrow Y) \geq 1$; model: J2(CC6L)

\begin{tabular}{|c|c|c|c|}
\hline$X \rightarrow Y$ & $\operatorname{supp}\left(^{*}\right)$ & $\operatorname{conf}\left(^{*}\right)$ & lift $\left(^{*}\right)$ \\
\hline$\{\mathrm{I}, \mathrm{P}\} \Rightarrow\{\mathrm{B}\}$ & 0.9041096 & 0.9510086 & 1.030024 \\
\hline$\{\mathrm{B}, \mathrm{I}\}=>\{\mathrm{P}\}$ & 0.9041096 & 0.9880240 & 1.027432 \\
\hline$\{\mathrm{B}\} \quad \Rightarrow\{\mathrm{P}\}$ & 0.9095890 & 0.9851632 & 1.024457 \\
\hline$\{\mathrm{P}\} \quad \Rightarrow\{\mathrm{B}\}$ & 0.9095890 & 0.9458689 & 1.024457 \\
\hline$\{\mathrm{B}, \mathrm{P}\} \quad>\{\mathrm{I}\}$ & 0.9041096 & 0.9939759 & 1.021975 \\
\hline$\{\mathrm{B}\} \quad \Rightarrow\{\mathrm{I}\}$ & 0.9150685 & 0.9910979 & 1.019016 \\
\hline$\{\mathrm{I}\} \quad>\{\mathrm{B}\}$ & 0.9150685 & 0.9408451 & 1.019016 \\
\hline$\{\mathrm{P}\} \quad \Rightarrow\{\mathrm{I}\}$ & 0.9506849 & 0.9886040 & 1.016452 \\
\hline$\{\mathrm{I}\} \quad \Rightarrow\{\mathrm{P}\}$ & 0.9506849 & 0.9774648 & 1.016452 \\
\hline
\end{tabular}

Tab. 10. Set of information about association rules with parameters of $\operatorname{supp}(X \rightarrow Y) \geq 0.4$; conf $(X \rightarrow Y) \geq 0.6$; lift $(X \rightarrow Y) \geq 0,8$; model: J3(CW8K)

\begin{tabular}{|c|c|c|c|}
\hline$X \rightarrow Y$ & $\operatorname{supp}\left(^{*}\right)$ & $\operatorname{conf}\left(^{*}\right)$ & lift $\left(^{*}\right)$ \\
\hline$\{\mathrm{H}\}=>\{\mathrm{C}\}$ & 0.4040404 & 0.7547170 & 1.1151788 \\
\hline$\{\mathrm{I}\}=>\{\mathrm{G}\}$ & 0.4141414 & 0.7068966 & 1.0291582 \\
\hline$\{\mathrm{I}\}=>\{\mathrm{C}\}$ & 0.4040404 & 0.6896552 & 1.0190427 \\
\hline$\{\mathrm{C}\}=>\{\mathrm{G}\}$ & 0.4343434 & 0.6417910 & 0.9343723 \\
\hline
\end{tabular}

Tab. 11. Set of information about association rules with parameters: $\operatorname{supp}(X \rightarrow Y) \geq 0.4 ; \operatorname{conf}(X \rightarrow Y) \geq 0.8$; lift $(X \rightarrow Y)>0.8 ;$ J4 $(C W 8 P)$

\begin{tabular}{|c|c|c|c|}
\hline$X \rightarrow Y$ & $\operatorname{supp}\left(^{*}\right)$ & $\operatorname{conf}\left(^{*}\right)$ & lift $\left(^{*}\right)$ \\
\hline$\{\mathrm{I}, \mathrm{O}\} \Rightarrow\{\mathrm{B}\}$ & 0.4411765 & 0.9375000 & 1.8389423 \\
\hline$\{\mathrm{O}\} \quad>\{\mathrm{B}\}$ & 0.4509804 & 0.8518519 & 1.6709402 \\
\hline$\{\mathrm{B}\} \Rightarrow\{\mathrm{O}\}$ & 0.4509804 & 0.8846154 & 1.6709402 \\
\hline$\{\mathrm{B}, \mathrm{I}\} \Rightarrow\{\mathrm{O}\}$ & 0.4411765 & 0.8823529 & 1.6666667 \\
\hline$\{\mathrm{B}\} \quad>\{\mathrm{I}\}$ & 0.5000000 & 0.9807692 & 1.3518711 \\
\hline$\{\mathrm{B}, \mathrm{O}\} \Rightarrow\{\mathrm{I}\}$ & 0.4411765 & 0.9782609 & 1.3484136 \\
\hline$\{\mathrm{O}\} \quad \Rightarrow\{\mathrm{I}\}$ & 0.4705882 & 0.8888889 & 1.2252252 \\
\hline$\{\mathrm{G}\} \quad \Rightarrow\{\mathrm{I}\}$ & 0.4901961 & 0.7142857 & 0.9845560 \\
\hline$\{\mathrm{C}\} \quad \Rightarrow\{\mathrm{I}\}$ & 0.4019608 & 0.7068966 & 0.9743709 \\
\hline
\end{tabular}


Tab. 12. Set of information about association rules with parameters: $\operatorname{supp}(X \rightarrow Y) \geq 0.1$; conf $(X \rightarrow Y) \geq 0.9$; lift $(X \rightarrow Y)>1.5$; J5(MF8K)

\begin{tabular}{|lc|c|c|c|}
\hline$X \rightarrow Y$ & $\operatorname{supp}\left(^{*}\right)$ & $\operatorname{conf}\left(^{*}\right)$ & lift $\left(^{*}\right)$ \\
\hline$\{\mathrm{F}, \mathrm{K}\} \Rightarrow\{\mathrm{H}\}$ & 0.1011905 & 1.0000000 & 1.768421 \\
\hline$\{\mathrm{I}, \mathrm{K}\} \quad>\{\mathrm{H}\}$ & 0.1428571 & 1.0000000 & 1.768421 \\
\hline$\{\mathrm{F}, \mathrm{I}, \mathrm{K}\} \quad \Rightarrow\{\mathrm{H}\}$ & 0.1011905 & 1.0000000 & 1.768421 \\
\hline$\{\mathrm{B}, \mathrm{I}, \mathrm{K}\} \Rightarrow\{\mathrm{H}\}$ & 0.1369048 & 1.0000000 & 1.768421 \\
\hline$\{\mathrm{K}\} \Rightarrow\{\mathrm{H}\}$ & 0.1428571 & 0.9600000 & 1.697684 \\
\hline$\{\mathrm{B}, \mathrm{K}\} \quad \Rightarrow\{\mathrm{H}\}$ & 0.1369048 & 0.9583333 & 1.694737 \\
\hline$\{\mathrm{E}, \mathrm{F}, \mathrm{H}\} \Rightarrow\{\mathrm{B}\}$ & 0.1607143 & 0.9642857 & 1.572816 \\
\hline$\{\mathrm{K}\} \quad \Rightarrow\{\mathrm{B}\}$ & 0.1428571 & 0.9600000 & 1.565825 \\
\hline$\{\mathrm{H}, \mathrm{K}\} \quad \Rightarrow\{\mathrm{B}\}$ & 0.1369048 & 0.9583333 & 1.563107 \\
\hline
\end{tabular}

Tab. 13. Set of information about association rules with parameters: $\operatorname{supp}(X \rightarrow Y) \geq 0.1 ; \operatorname{conf}(X \rightarrow Y) \geq 0.8$; lift $(X \rightarrow Y)>1.5 ;$ J6 $(M F 8 P)$

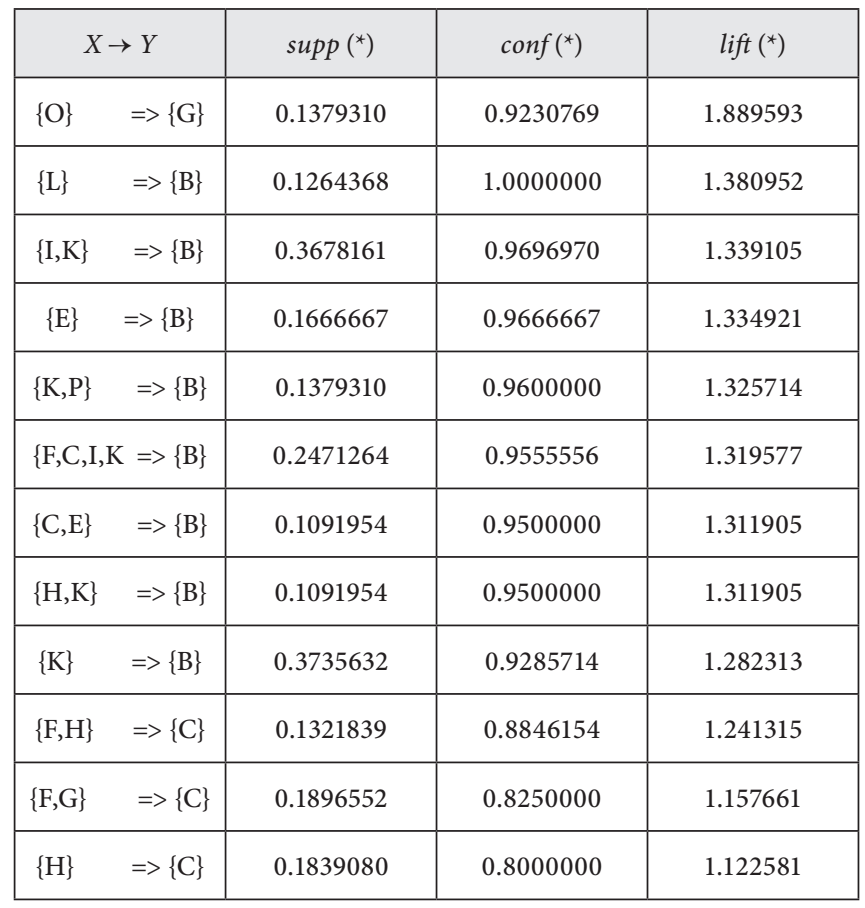

Due to the lack of information about situations in which there is no "A" defect, it was assumed that it is independent and the rules in which it participates were not considered. First, sets of rules were defined to define the relationship between defects during the production of individual models. The next stage of the dependency analysis focused on defects that rarely appear (Fig. 9).

Table 14 Set of information about association rules with parameters: model: CC6LA, CW6L, CW8K, CW8P, MF8K, MF8P, $\mathrm{n}=1450$, The obtained rules were saved in Table 12 . Symbols indicate high (•), medium (•), and low (०) trust in the rule for the selected model.

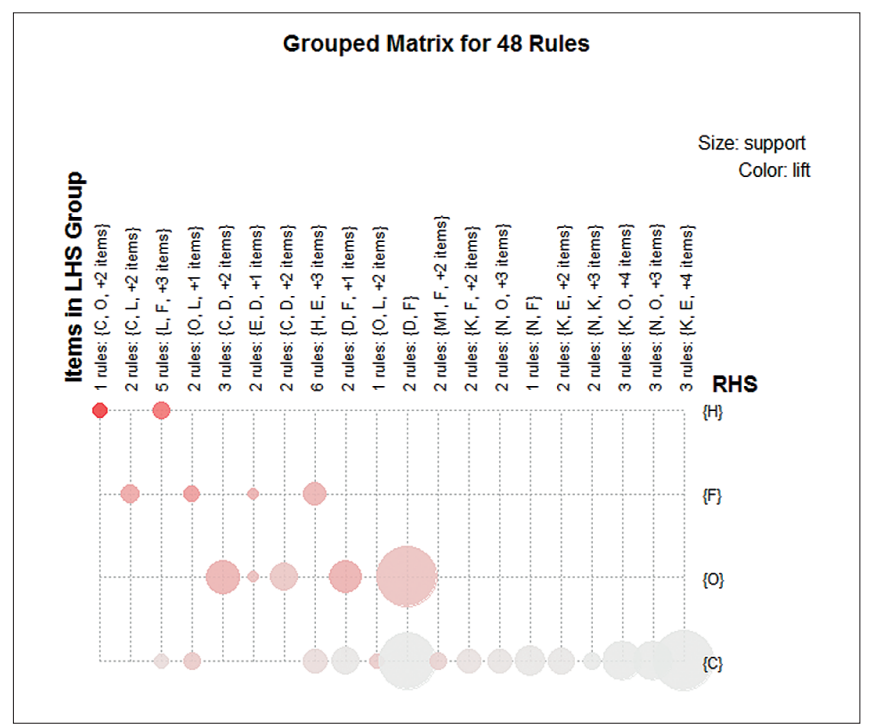

Fig. 9. Grouped matrix for 48 rules, where lift $>1$ (Model: J1CC6LA, J2CC6LA, J3CW8K, J4CW8P, J5MF8K, J6MF8P, supp $=0.1, \operatorname{conf}=0.8, n=1450)$

Tab. 14. Set of information about association rules with parameters: model: J1(C6LA), J2(CC6L), J3(CW8K), J4(CW8P), J5(MF8K), J6(MF8P), $n=1450$

\begin{tabular}{|c|c|c|c|c|c|c|}
\hline$X \rightarrow Y$ & $\mathrm{~J} 1$ & $\mathrm{~J} 2$ & J3 & $\mathrm{J} 4$ & J5 & J6 \\
\hline\{\}$=>\{\mathrm{A}\}$ & - & - & $\bullet$ & $\bullet$ & $\bullet$ & $\bullet$ \\
\hline$\{E\}=>\{B\}$ & $\circ$ & $\circ$ & $\circ$ & $\circ$ & $\circ$ & - \\
\hline$\{\mathrm{I}\}=>\{\mathrm{B}\}$ & $\bullet$ & - & $\circ$ & $\circ$ & $\circ$ & $\circ$ \\
\hline$\{\mathrm{K}\}=>\{\mathrm{B}\}$ & $\circ$ & 。 & $\circ$ & 。 & • & $\bullet$ \\
\hline$\{\mathrm{L}\}=>\{\mathrm{B}\}$ & $\circ$ & $\circ$ & $\circ$ & $\circ$ & $\circ$ & - \\
\hline$\{\mathrm{O}\} \Rightarrow\{\mathrm{B}\}$ & $\circ$ & $\circ$ & - & - & $\circ$ & $\circ$ \\
\hline$\{\mathrm{P}\}=>\{\mathrm{B}\}$ & - & - & $\circ$ & $\circ$ & $\circ$ & $\circ$ \\
\hline$\{\mathrm{C}, \mathrm{E}\} \Rightarrow\{\mathrm{B}\}$ & $\circ$ & $\circ$ & $\circ$ & $\circ$ & $\circ$ & - \\
\hline$\{\mathrm{H}, \mathrm{K}\} \Rightarrow>\mathrm{B}\}$ & $\circ$ & $\circ$ & $\circ$ & $\circ$ & - & - \\
\hline$\{\mathrm{I}, \mathrm{K}\} \Rightarrow>\mathrm{B}\}$ & $\circ$ & $\circ$ & $\circ$ & $\circ$ & $\circ$ & - \\
\hline$\{\mathrm{I}, \mathrm{P}\}=>\{\mathrm{B}\}$ & • & • & $\circ$ & $\circ$ & $\circ$ & $\circ$ \\
\hline$\{\mathrm{K}, \mathrm{P}\} \Rightarrow\{\mathrm{B}\}$ & $\circ$ & $\circ$ & $\circ$ & $\circ$ & $\circ$ & - \\
\hline$\{\mathrm{E}, \mathrm{F}, \mathrm{H}\} \Rightarrow\{\mathrm{B}\}$ & $\circ$ & $\circ$ & $\circ$ & $\circ$ & - & $\circ$ \\
\hline$\{\mathrm{F}, \mathrm{C}, \mathrm{I}, \mathrm{K}\} \Rightarrow\{\mathrm{B}\}$ & $\circ$ & $\circ$ & $\circ$ & $\circ$ & $\circ$ & - \\
\hline$\{\mathrm{D}\}=>\{\mathrm{C}\}$ & - & - & - & - & $\cdot$ & - \\
\hline$\{\mathrm{H}\}=>\{\mathrm{C}\}$ & $\circ$ & $\circ$ & - & $\circ$ & $\circ$ & $\bullet$ \\
\hline$\{\mathrm{I}\}=>\{\mathrm{C}\}$ & $\circ$ & $\circ$ & - & $\circ$ & $\circ$ & $\circ$ \\
\hline$\{\mathrm{E}, \mathrm{F}, \mathrm{H}, \mathrm{L}\} \Rightarrow\{\mathrm{C}\}$ & - & - & - & - & - & - \\
\hline$\{\mathrm{F}, \mathrm{G}\}=>\{\mathrm{C}\}$ & $\circ$ & $\circ$ & $\circ$ & $\circ$ & $\circ$ & - \\
\hline$\{\mathrm{F}, \mathrm{H}\} \Rightarrow\{\mathrm{C}\}$ & $\circ$ & $\circ$ & $\circ$ & $\circ$ & $\circ$ & • \\
\hline$\{\mathrm{F}, \mathrm{H}, \mathrm{L}\} \Rightarrow\{\mathrm{C}\}$ & - & - & - & - & - & - \\
\hline$\{\mathrm{F}, \mathrm{H}, \mathrm{L}, \mathrm{O}\} \Rightarrow\{\mathrm{C}\}$ & - & - & - & - & - & - \\
\hline$\{\mathrm{F}, \mathrm{M}\} \quad \Rightarrow\{\mathrm{C}\}$ &. & - & - & - & - & - \\
\hline$\{\mathrm{H}, \mathrm{L}\} \quad \Rightarrow\{\mathrm{C}\}$ & - & - & - & - & - & - \\
\hline$\{\mathrm{H}, \mathrm{L}, \mathrm{O}\} \Rightarrow>\{\mathrm{C}\}$ or $\{\mathrm{F}\}$ & - & - & - & - & - & - \\
\hline$\{\mathrm{C}, \mathrm{H}, \mathrm{L}, \mathrm{O}\}=>\{\mathrm{F}\}$ & - & - & - & - & - & - \\
\hline$\{C\} \Rightarrow\{G\}$ & $\circ$ & $\circ$ & - & $\circ$ & $\circ$ & $\circ$ \\
\hline$\{\mathrm{I}\}=>\{\mathrm{G}\}$ & $\circ$ & 。 & - & 。 & 。 & 。 \\
\hline
\end{tabular}


Tab. 14. Set of information about association rules with parameters: model: J1(C6LA), J2(CC6L), J3(CW8K), J4(CW8P), J5(MF8K), J6(MF8P), $n=1450$

\begin{tabular}{|c|c|c|c|c|c|c|}
\hline$X \rightarrow Y$ & J1 & $\mathrm{J} 2$ & $\mathrm{J3}$ & $\mathrm{J} 4$ & $\mathrm{~J} 5$ & J6 \\
\hline$\{\mathrm{O}\}=>\{\mathrm{G}\}$ & 。 & 。 & $\circ$ & 。 & 。 & • \\
\hline$\{\mathrm{B}, \mathrm{K}\}=>\{\mathrm{H}\}$ & $\circ$ & $\circ$ & 。 & 。 & • & 。 \\
\hline$\{\mathrm{B}, \mathrm{I}, \mathrm{K}\} \Rightarrow>\mathrm{H}\}$ & 。 & $\circ$ & 。 & 。 & - & 。 \\
\hline$\{\mathrm{C}, \mathrm{F}, \mathrm{L}, \mathrm{O}\} \Rightarrow\{\mathrm{H}\}$ & - & - & - & - & - & - \\
\hline$\{\mathrm{F}, \mathrm{K}\}=>\{\mathrm{H}\}$ & $\circ$ & $\circ$ & $\circ$ & 。 & - & 。 \\
\hline$\{\mathrm{F}, \mathrm{I}, \mathrm{K}\}=>\{\mathrm{H}\}$ & $\circ$ & $\circ$ & 。 & 。 & - & 。 \\
\hline$\{\mathrm{F}, \mathrm{L}, \mathrm{O}\} \Rightarrow\{\mathrm{H}\}$ & - & - & - & - & - & - \\
\hline$\{\mathrm{I}, \mathrm{K}\} \Rightarrow>\{\mathrm{H}\}$ & $\circ$ & $\circ$ & $\circ$ & 。 & • & 。 \\
\hline$\{\mathrm{K}\} \Rightarrow>\mathrm{H}\}$ & $\circ$ & $\circ$ & $\circ$ & 。 & • & 。 \\
\hline$\{\mathrm{B}\}=>\{\mathrm{I}\}$ & - & - & 。 & • & 。 & 。 \\
\hline$\{\mathrm{B}, \mathrm{O}\}=>\{\mathrm{I}\}$ & $\circ$ & $\circ$ & $\circ$ & $\cdot$ & 。 & 。 \\
\hline$\{\mathrm{B}, \mathrm{P}\}=>\{\mathrm{I}\}$ & - & $\bullet$ & $\circ$ & $\circ$ & 。 & 。 \\
\hline$\{\mathrm{O}\}=>\{\mathrm{I}\}$ or $\{\mathrm{B}\}$ & $\circ$ & $\circ$ & $\circ$ & $\bullet$ & 。 & 。 \\
\hline$\{\sim \mathrm{C}\}=>\{\mathrm{I}\}$ & $\circ$ & $\circ$ & $\circ$ & . & - & 。 \\
\hline$\{\sim \mathrm{G}\} \Rightarrow\{\mathrm{I}\}$ & $\circ$ & $\circ$ & $\circ$ & - & 。 & 。 \\
\hline$\{\mathrm{P}\}=>\{\mathrm{I}\}$ & - & - & $\circ$ & 。 & 。 & 。 \\
\hline$\{\mathrm{B}\}=>\{\mathrm{O}\}$ & $\circ$ & $\circ$ & $\circ$ & • & 。 & 。 \\
\hline$\{\mathrm{C}, \mathrm{D}, \mathrm{H}\}=>\{\mathrm{O}\}$ & - & - & . & - & - & - \\
\hline$\{\mathrm{C}, \mathrm{D}, \mathrm{F}, \mathrm{H}\} \Rightarrow\{\mathrm{O}\}$ & - & - & - & - & - & - \\
\hline$\{\mathrm{D}\}=>\{\mathrm{O}\}$ & - & - & - & - & - & - \\
\hline$\{\mathrm{D}, \mathrm{H}\}=>\{\mathrm{O}\}$ & $\cdot$ & - & - & - & - & - \\
\hline$\{\mathrm{D}, \mathrm{F}, \mathrm{H}\} \Rightarrow\{\mathrm{O}\}$ & $\cdot$ & - & - & - & - & - \\
\hline$\{B\}=>\{P\}$ & - & - & $\circ$ & 。 & 。 & 。 \\
\hline$\{\mathrm{B}, \mathrm{I}\}=>\{\mathrm{P}\}$ & • & $\bullet$ & $\circ$ & 。 & 。 & 。 \\
\hline$\{\mathrm{I}\}=>\{\mathrm{P}\}$ & • & • & $\circ$ & 。 & 。 & 。 \\
\hline
\end{tabular}

In manual production it is very easy to get air bubbles in the laminate, therefore the $\operatorname{defect}(\mathrm{A})$ occurs with such a high probability coefficient. The rules obtained can be logically justified, because the deformed gelcoat is repaired by grinding and rebuilding the correct gelcoat layer. Grinding is necessary in case of defects: scratches to be sanded, cracks, deformations, hardener stains and drops, and glass under-saturation. The occurrence of anti-skid damage is repaired by grinding and removing a fairly large surface and supplementing with new elements. Wearing defects, cracks, anti-skid damage and hardener stains often contribute to the deformation defect. The anti-skid failure defect most often coexists with the following defects: surpluses to grind, gel coat deformations as well as cracks and deformations.

Not all the observed relationships can be easily justified. They could have had a more complex basis. The possible reasons for their existence should be considered more deeply and analysed, for example, if there is an defect of "mold defects" and "matt surface", then there is also a "burn" defect. The relationship between defects: "burns" and "mold defects", which can be observed during the production of selected models, requires more consideration. Additionally, the relationship between defects: "porosity" and "deformation"; "Anti-skid damage" and "rebound fibers";

The low probability of defects resulting from "deformation" and "defects to be ground" is puzzling - these defects should have a high confidence factor.

An interesting rule was generated for the CW8K model. For $64 \%$ of the units the following relationship was confirmed: defect: "fiber reflections" occurs if there was no "surpluses to grind" defect. The observation may result if there are allowances for grinding, it is most often because the layer of gelcoat was too thick, and the defect of "fiber reflection" occurs when the gelcoat is too thin. Rules whose successor contains a "burn" defect are quite common in the resulting set. This can be justified by a fairly large number of occurrences of this defect, as they may not have practical justification.

\section{SUMMARY}

The article reveals the dependencies of the occurrences of specific defects, which were shown by association and formulation of the association rules. Grouping of defects and their dependencies can allow for better monitoring, control, and implementation of prevention activities, which can allow minimization of repair costs and avoidance of additional costs.

This work used the Apriori algorithm and association methods. The research was conducted on data acquired from the lamination process of one chosen yacht. To perform the simulation, a sample size of 1450 samples observed in 2013-2017 was used. Execution of the algorithm allowed the formulation of a set of association rules which can be used to specify the certainty of occurrence of a given defect. Finding dependencies can reduce uncertainty in the occurrence of specific defects and lead to improvement of quality and reduction of costs. The use of new methods and tools backed by artificial intelligence relating to Big Data allows better management of uncertainty and complexity.

\section{REFERENCES}

1. Amran, Y. M., Alyousef, R., Rashid, R. S., Alabduljabbar, H., \& Hung, C. C.: Properties and applications of FRP in strengthening RC structures: A review. In Structures, Vol. 16, pp. 208-238, Elsevier 2018.

2. Agrawal, R., R. Srikant: Fast Algorithms for Mining Association Rules in Large Databases, Journal of Computer Science and Technology. 15, 1994, 487-499.

3. Alizadeh, F., Sutherland, L. S., \& Soares, C. G.: Effect of vacuum bag pressure on the flexural properties of GFRP composite laminates. Maritime technology and engineering, 3, 2016, 429-434. 
4. Bolf, D., Zamarin, A., \& Basan, R.: Composite Material Damage Processes. Pomorski zbornik, (3), 2020, 307-323.

5. Bossi, R. H., \& Giurgiutiu, V.: Nondestructive testing of damage in aerospace composites. In Polymer Composites in the Aerospace Industry, Woodhead Publishing 2015, 413-448.

6. Bugg, D.: New D-Iso/NPG gelcoat offers exceptional UV colour stability: Feature Marine. JEC composites, (67), 2011, 42-46.

7. Calabrese, L., Di Bella, G., \& Fiore, V.: Manufacture of marine composite sandwich structures. In Marine Applications of Advanced Fibre-Reinforced Composites, Woodhead Publishing 2016, 57-78.

8. Castegnaro, S., Gomiero, C., Battisti, C., Poli, M., Basile, M., Barucco, P., ... \& Lazzaretto, A.: A bio-composite racing sailboat: Materials selection, design, manufacturing and sailing. Ocean Engineering, 133, 2017, 142-150.

9. Cpalka, K., K. Łapa, A. Przybył: A New Approach to Design of Control Systems Using Genetic Programming, Information Technology and Control. 44, 2015, 433-442.

10. Cucinotta, F., Guglielmino, E., \& Sfravara, F.: Life cycle assessment in yacht industry: A case study of comparison between hand lay-up and vacuum infusion. Journal of cleaner production, 142, 2017, 3822-3833.

11. Fragassa C.: Marine Applications of Natural FibreReinforced Composites: A Manufacturing Case Study. In: Pellicer E. et al. (eds) Advances in Applications of Industrial Biomaterials. Springer, Cham. 2017, https://doi. org/10.1007/978-3-319-62767-0_2.

12. Gaiotti, M., \& Rizzo, C. M.: Buckling behavior of FRP sandwich panels made by hand layup and vacuum bag infusion procedure. Rizzuto \& Guedes Soares (eds), Sustainable Maritime Transportation and Exploitation of Sea Resources, 2011, 385-392.

13. Gełesz, P., Karczewski, A., Kozak, J., Litwin, W., \& Piątek, Ł.: Design methodology for small passenger ships on the example of the ferryboat Motława 2 driven by hybrid propulsion system. Polish Maritime Research, 24(s1), 2017, 67-73.

14. Gombos, Z. J., \& Summerscales, J.: In-mould gel-coating for polymer composites. Composites Part A: Applied Science and Manufacturing, 91, 2016, 203-210.

15. Hashin, Z.: Failure Criteria for Unidirectional Fiber Composites 1, 1980.

16. Hassen, A. A., Taheri, H., \& Vaidya, U. K.: Non-destructive investigation of thermoplastic reinforced composites. Composites Part B: Engineering, 97. 2016, 244-254.
17. Hoge, J., \& Leach, C., Epoxy resin infused boat hulls. Reinforced Plastics, 60(4), 2016, 221-223.

18. Jang, J. W., Jeong, S., Oh, D., Cho, J. H., \& Noh, J.: Test and Evaluation Procedure of Foam Core Materials for Composite Ships. Journal of the Korean Society of Marine Environment \& Safety, 26(3), 2020, 286-296.

19. Kozioł, M., Wieczorek, J., \& Hekner, B.: Surface quality and mechanical properties of epoxy-glass fibre laminates manufactured by RTM method with use of gelcoat. Composites Theory and Practice (Kompozyty), 16(3), 2016, 189-195.

20. Landowski, M., Budzik, M., \& Imielińska, K. (2011). On degradation of glass / polyester laminate immersed in water. Advances in Materials Science, 11 (1), 35-39.

21. Landowski, M., \& Imielińska, K.: Degradation of GFRP Marine Laminates with Nano Particle Modified Coatings, Advances in Materials Science, 13(2), 2013, 19-22., doi: https://doi. org/10.2478/adms-2013-0006.

22. Landowski, M., Budzik, M., \& Imielińska, K., Water sorption and blistering of GFRP laminates with varying structures. Advances in materials science, 12(4), 2013 23-29.

23. Landowski, M., Budzik, M., \& Imielińska, K. Water absorption and blistering of glass fibre-reinforced polymer marine laminates with nanoparticle-modified coatings. Journal of Composite Materials, 48(23), 2014, 2805-2813.

24. Liu Cai-yanYoufa SunYoufa Sun, Application of Data Mining in Production Quality Management, Conference: Intelligent Information Technology Application, 2009. IITA 2009. Third International Symposium on Volume: 2, DOI: 10.1109/ IITA.2009.81.

25. Mathijsen, D. Designing boats for the Volvo Ocean Race: An ongoing process of optimization and finding the right compromise. Reinforced Plastics, 62(4), 2018, 203-207.

26. Mehmed Kantardzic. Data Mining: Concepts, Models, Methods, and Algorithms. Wiley-IEEE Press.2002.10

27. Mouritz, A. P., Gellert, E., Burchill, P., \& Challis, K. Review of advanced composite structures for naval ships and submarines. Composite structures, 53(1), 2001 21-42.

28. Musio-Sale, M., Nazzaro, P. L., \& Peterson, E. Visions, Concepts, and Applications in Additive Manufacturing for Yacht Design. In International Conference on Applied Human Factors and Ergonomics (pp. 401-410). Springer, Cham. 2019, July.

29. Naik, N. K., Sirisha, M., \& Inani, A. Permeability characterization of polymer matrix composites by RTM/VARTM. Progress in aerospace sciences, 65, 2014, 22-40. 
30. Neşer, G. Polymer based composites in marine use: history and future trends. Procedia engineering, 194, 2017, 19-24.

31. Nikbakt, S., Kamarian, S., \& Shakeri, M. A review on optimization of composite structures Part I: Laminated composites. Composite Structures, 195, 2018, 158-185.

32. Niksa-Rynkiewicz, T., \& Witkowska, A. Analysis of Impact of Ship Model Parameters on Changes of Control Quality Index in Ship Dynamic Positioning System, Polish Maritime Research, 26(1), 2019, 6-14. doi: https://doi.org/10.2478/ pomr-2019-0001.

33. Nowak, B.A., R.K. Nowicki, M. Woźniak, C. Napoli: Multiclass Nearest Neighbour Classifier for Incomplete Data Handling, in: Springer, Cham, 2015, 469-480.

34. Oral, I.: Characterization of damages in materials by computeraided tap testing. In IOP Conference Series: Materials Science and Engineering, Vol. 707, No. 1, p. 012019, IOP Publishing, 2019.

35. Osborne, T., An introduction to resin infusion. Reinforced Plastics, 58(1), 2014, 25-29.

36. Podsiadlo, A., W. Tarelko: Modelling and Developing a Decision-Making Process of Hazard Zone Identification in Ship Power Plants. International Journal of Pressure Vessels and Piping. 83, 2006, 287-298. doi.org/10.1016/j. ijpvp.2006.02.017.

37. Pomázi, Á., \& Toldy, A. Multifunctional gelcoats for fiber reinforced composites. Coatings, 9(3), 2019, 173.

38. Quattrocchi, A., Freni, F., \& Montanini, R., Air-coupled ultrasonic testing to estimate internal defects in composite panels used for boats and luxury yachts. International Journal on Interactive Design and Manufacturing (IJIDeM), 14(1), 2020, 35-41.

39. Ray, B. C., \& Rathore, D., Environmental damage and degradation of FRP composites: A review report. Polymer Composites, 36(3), 2015, 410-423.

40. Rubino, F., Nisticò, A., Tucci, F., \& Carlone, P., Marine application of fiber reinforced composites: a review. Journal of Marine Science and Engineering, 8(1), 2020, 26.

41. Scott, R.J.: Fiberglass Boat Design and Construction, Society of Naval Architects and Marine Engineers, 1996.

42. Singha, M., \& Singha, K., Applications of textiles in marine products. Marine Science, 2(6), 2012, 110-119.

43. Smoleń, J., Cyganek, A., \& Kozioł, M., Manufacture of transmission housing by contact layer technique using vacuum bag. Compos. Theory Pract, 19, 2019, 18-22.
44. Sørensen, S. N., \& Lund, E., Topology and thickness optimization of laminated composites including manufacturing constraints. Structural and Multidisciplinary Optimization, 48(2), 2013, 249-265.

45. Stewart, R., Better boat building-trend to closed-mould processing continues. Reinforced plastics, 55(6), 2011, 30-36.

46. Such M., Ward C., Hutabarat W., Tiwari A., Intelligent Composite Layup by the Application of Low Cost Tracking and Projection Technologies, Procedia CIRP, 25, 2014, 122131, https://doi.org/10.1016/j.procir.2014.10.020.

47. Summerscales, J., Hoppins, C., Anstice, P., Brooks, N., Wiggers, J., Yahathugoda, D., ... \& Cooper, M., In-mould gel coating for resin transfer moulding. In The 10 th International Conference on Flow Processes in Composite Materials (FPCM10), Monte Verità, Ascona, CH-July, 2010, 11-15.

48. Taggart, R.: Ship Design and Construction, 10048th ed., The Society of Naval Architects and Marine Engineers, One World Trade Center, New York, 1980.

49. Tarelko, W., T. Kowalewski: Modeling of Decision-Making Process Relating to Design of Ship Power Plants Safe for Operators, in: 2013 12th Mexican International Conference on Artificial Intelligence, IEEE, 2013, 17-23. DOI: 10.1109/ MICAI.2013.8.

50. www.jp.scottbader.com/uploads/files/5527_gelcoat-qualityguide-english.pdf.

51. www.westsystem.com/wp-content/uploads/FiberglassManual-2015.pdf. 


\section{CONTACT WITH THE AUTHORS}

\section{Tacjana Niksa-Rynkiewicz}

e-mail:tacniksa@pg.edu.pl

Gdańsk University of Technology

11/12 Gabriela Narutowicza Street, 80-233 Gdańsk

Poland

Michal Landowski

e-mail: miclando@pg.edu.pl

Gdańsk University of Technology

11/12 Gabriela Narutowicza Street, 80-233 Gdańsk

Poland

\section{Paweł Szalewski}

e-mail:pawel.szalewski@pg.edu.pl

Gdańsk University of Technology

11/12 Gabriela Narutowicza Street, 80-233 Gdańsk

Poland 